\title{
The Adverse Effects of Tamsulosin in Men with Benign Prostatic Hyperplasia, a Review of the Literature
}

\author{
Nathan Walter Leibacher, Marcello Henrique Araujo Da Silva* \\ Urogenital Research Unit, Rio de Janeiro State University, Rio de Janeiro, Brazil \\ Email address: \\ marcellohas@yahoo.com.br (M. H. A. Da Silva) \\ ${ }^{*}$ Corresponding author

\section{To cite this article:} \\ Nathan Walter Leibacher, Marcello Henrique Araujo Da Silva. The Adverse Effects of Tamsulosin in Men with Benign Prostatic \\ Hyperplasia, a Review of the Literature. American Journal of Life Sciences. Special Issue: Advances in Urology and Nephrology in the 21st \\ Century. Vol. 7, No. 4, 2019, pp. 68-74 doi: 10.11648/j.ajls.20190704.11
}

Received: August 14, 2019; Accepted: August 22, 2019; Published: September 11, 2019

\begin{abstract}
In the United States, tamsulosin is the most prescribed drug for benign prostatic hyperplasia (BPH) treatment. However, less is known about the adverse effects and mechanism of action of the drug in the organism. So, the aim of this review is to evaluate the benefits and harms of tamsulosin therapy in patients with BPH. A literature analysis was realized using the database of the National Center for Biotechnology Information (NCBI) MEDLINE®. The data collection was carried out in a retrospective of 10 years from 2008. Thus, we considered some measurements parameters used in different studies for a reliable comparison of the works. Tamsulosin has been characterized as an effective treatment for BPH. However, some studies demonstrate that the epithelial elements remain proliferative even after the administration of the drug and may be involved in the continuous growth of the gland. Also, tamsulosin can directly impact on the ejaculation process, cognitive functions and mental health of men. BPH affects approximately $50 \%$ of men between 50 and 60 years old. Beyond that, $90 \%$ of men in their eighth decade of life will present anatomical evidence of BPH. Therefore, the treatment with tamsulosin, an $\alpha 1-$ adrenergic antagonist that promotes the relaxation of the prostate smooth muscle, is essential to diminish the gland size and restore the urinary flow. However, its administration must be assessed for a better response and lower risk of adverse effects in those patients.
\end{abstract}

Keywords: Tamsulosin, Benign Prostatic Hyperplasia, Lower Urinary Tract Symptoms, Adverse Effects, Alpha Antagonist, Prostate

\section{Introduction}

Benign Prostatic Hyperplasia (BPH) affects $50 \%$ of men between 50 and 60 years of age and approximately $90 \%$ of men in the eighth decade of life will present anatomical evidence of BPH [1-4]. This pathology is characterized by the proliferation of both smooth muscle cells of the stroma and prostatic epithelial cells, which gradually modify the structure of the organ and cause its increase [5,6].

Prostate development occurs in three distinct phases throughout a man's life. In the fetal stage, occurs the primary development which is resumed during puberty. In the second phase occurs the differentiation and transition to the adultlike gland. In adulthood, the prostate enlarges over time in only one of its anatomic areas (anterior lobe, middle lobe, posterior lobe, left lateral lobe and right lateral lobe), which at one time may manifest classic obstructive symptoms of BPH $[5,7]$.

Some studies indicate that the proliferation of the stromatic and epithelial elements could be correlated to the imbalance between growth factors and steroid hormones that are found inside the gland. Physiologically, the interaction between these molecules would coordinate the rate of proliferation and cell death $[5,8]$.

In this way, the exacerbated and abnormal proliferation of prostate cells causes glandular growth and compression of adjacent structures, resulting in obstruction of the urinary flow. This dynamic affects directly the patients' quality of life [8-10]. The Lower Urinary Tract Symptoms (LUTS) are classified in obstructive symptoms (reduced urinary flow and incomplete voiding of the bladder) and bothering symptoms (increased frequency of urination, nocturia, urinary urgency 
and burning when urinating) [11-13].

The main pharmacological treatment line indicated by the American Urology Association and the European Association of Urology for BPH are the inhibitors of the 5-alfa-reductase (5-ARI) [14-18]. However, these drugs generate many adverse effects, including the alteration of the corpus cavernosum morphology and the reduction of nitric oxide synthesis in the vascular endothelium [19, 20].

To diminish these adverse effects, some lines of pharmacological treatments and protocols have been reviewed, in which the tamsulosin therapy is highlighted. Tamsulosin was the $45^{\text {th }}$ most prescribed drug in the United States in 2017 [21] and it is part of the class of selective $\alpha$ blockers for subtype 1A [13, 22, 23].

The majority of adrenergic receptors found in the prostate gland are part of the subtype $\alpha 1 \mathrm{~A}$ that are correlated with the contraction of the stromal smooth muscle. The $\alpha 1 \mathrm{~B}$ receptors are predominant in the smooth muscle of the tunica media, in the arteries and veins. There, $\alpha 1 \mathrm{~B}$ receptors guarantee the vascular tone and regulate the vasoconstriction process.

Thus, tamsuloin, as an $\alpha$-blocker $1 \mathrm{~A}$, has a therapeutic advantage over non-specific $\alpha$-blockers, since they interact with booth $\alpha 1 \mathrm{~A}$ and $\alpha 1 \mathrm{~B}$ receptors. Blockade of $\alpha 1 \mathrm{~B}$ receptors causes vascular smooth muscle relaxation, that can result in severe hypotension as the main adverse effect. Tamsulosin, however, proves to be safer in this regard because of its selectivity [12, 23, 24].

While some tamsulosin effects are well known, many others are not a consensus in the scientific community. Therefore, the present literature review seeks to determinate the updates of BPH treatment with tamsulosin in order to expose and analyze the benefits and harms related to its administration.

\section{Methods}
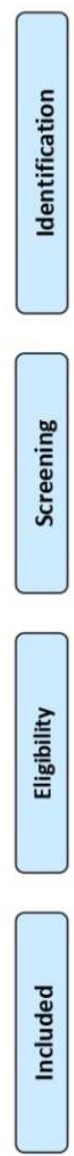

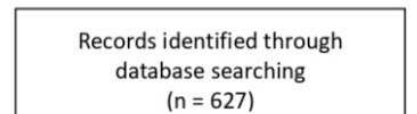

Additional records identified through other sources $(n=0)$

$(n=627)$
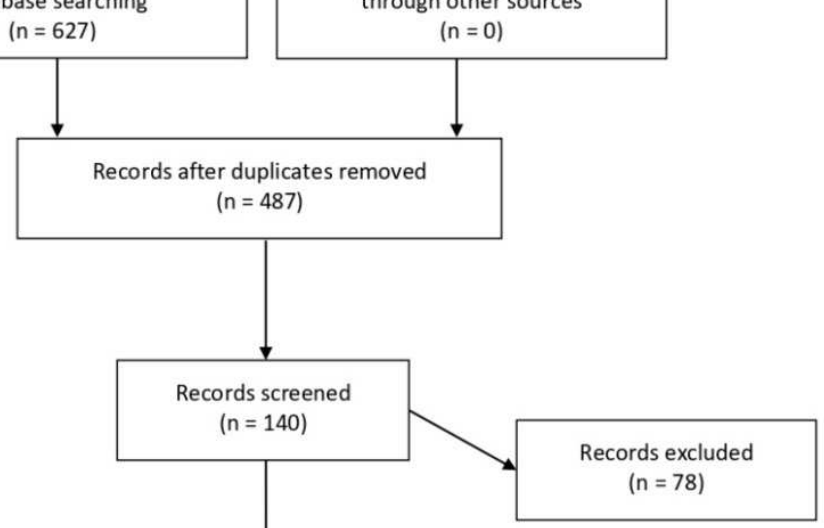

Studies included in

qualitative synthesis $(n=51)$ 
A literature analysis was realized using the database of the National Center for Biotechnology Information (NCBI) MEDLINE®, from the PubMed tool. The Medical Subject Heading (MeSH) and key-words used for identification of relevant studies were "tamsulosin", "benign prostatic hyperplasia", "lower urinary tract symptoms", "BPH" and "LUTS". The data collection was carried out in a retrospective of 10 years from 2008. Thus, we considered some measurements parameters used in different studies for a reliable comparison of the works.

For this, the following parameters were validated: International Prostate Symptom Score (IPSS), which consist in seven questions about the symptoms and one question about the quality of life, classifying the patients according to the severity of the symptoms in mild, moderate and severe; Prostate Volume (PV), which evaluates the size of the gland by transurethral ultrasound; Maximum Flow Rate (Qmax) that determines the maximum urinary flow through uroflowmetry; and IPSS-QoL (Quality of Life) that consists of subjective questions about the patient coexistence with BPH. Other parameters of evaluation were used in some articles, as The International Index of Erectile Function (IIEF-5), important in the correlation between LUTS treatment with tamsulosin and erectile dysfunction.

In the data identification period, 627 articles were found. Among them, divergent articles were excluded from the subject matter. Economic analysis, pharmacodynamic approaches, drug interactions, dose adjustments, combined therapies, and clinical trials were excluded. In the end, 140 articles were evaluated within the established parameters. Thus,
62 articles followed for eligibility and among them, 11 were excluded due to failures or inconsistencies. Therefore, 51 articles were included in the analysis of this review [figure 1].

\section{Results}

Data from the articles included in this study showed aspects concerning the effects of tamsulosin. According to Wein et al., Aslan et al. and Rosen et al. the presence of LUTS associated with BPH is a major factor for the development of sexual dysfunction. Therefore, the therapy with tamsulosin could act as a predisposing factor for even higher risk of sexual dysfunction. However, some studies demonstrated that the drug does not alter this function, as shown by Matsushita et al., Kim et al., Seo et al. and Traish et al. For Shelbaia et al., the tamsulosin treatment showed improvement in erectile function and sexual desire. Choi et al. found that patients receiving tamsulosin had a better profile of premature ejaculation. Overall, the majority of placebo-controlled studies showed that tamsulosin could have some impact on those sexual functions and cause abnormalities.

The quality of life in patients with LUTS/BPH appears to increase when treated with tamsulosin. Yoshida et al. and Kim et al. showed the impact that symptoms regression could do on men mental health. Other effects correlated with this treatment is a higher risk of hypotension, as demonstrated by the study of Bird et al. and a higher risk of developing dementia found by the researcher Duan et al. The findings are summarized in Table 1.

Table 1. Effects of Tamsulosin and 5-ARIs in different studies.

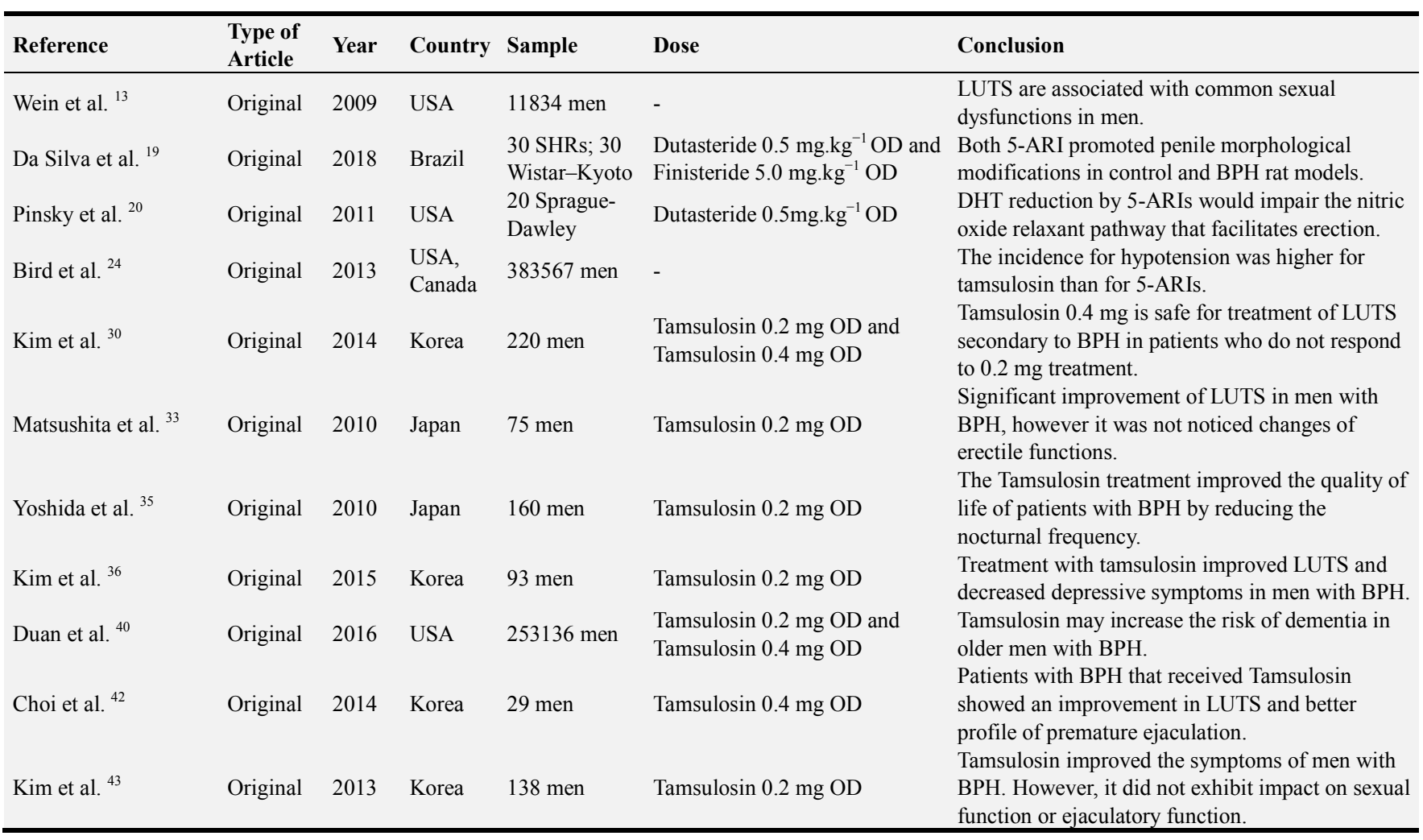




\begin{tabular}{|c|c|c|c|c|c|c|}
\hline Reference & $\begin{array}{l}\text { Type of } \\
\text { Article }\end{array}$ & Year & Country & Sample & Dose & Conclusion \\
\hline Yu et al. ${ }^{45}$ & Original & 2011 & Taiwan & 209 men & $\begin{array}{l}\text { Tamsulosin } 0.2 \mathrm{mg} \text { OD and } \\
\text { Silodosin } 4.0 \mathrm{mg} \text { twice a day }\end{array}$ & $\begin{array}{l}\text { The trial shows the non-inferiority of Silodosin to } \\
\text { Tamsulosin in patients with symptoms of BPH. }\end{array}$ \\
\hline Seo et al. ${ }^{46}$ & Original & 2010 & Korea & $57 \mathrm{men}$ & $\begin{array}{l}\text { Tamsulosin } 0.2 \mathrm{mg} \text { OD and } \\
\text { Solifenacin } 5.0 \mathrm{mg} \text { OD }\end{array}$ & $\begin{array}{l}\text { The combination therapy with Tamsulosin and } \\
\text { Solifenacin was effective for LUTS, but not to } \\
\text { erectile function. }\end{array}$ \\
\hline Shelbaia et al. ${ }^{47}$ & Original & 2011 & Egypt & 60 men & Tamsulosin $0.2 \mathrm{mg}$ OD & $\begin{array}{l}\text { Tamsulosin showed an improvement on the } \\
\text { erectile function and sexual desire. }\end{array}$ \\
\hline Pande et al. ${ }^{48}$ & Original & 2014 & India & $53 \mathrm{men}$ & $\begin{array}{l}\text { Tamsulosin } 0.4 \mathrm{mg} \text { OD and } \\
\text { Silodosin } 8.0 \mathrm{mg} \text { OD }\end{array}$ & $\begin{array}{l}\text { Silodosin is comparable to Tamsulosin in the } \\
\text { treatment of BPH. However, retrograde } \\
\text { ejaculation can be caused as an adverse effect. }\end{array}$ \\
\hline Traish et al. ${ }^{49}$ & Original & 2015 & USA & 470 men & $\begin{array}{l}\text { Tamsulosin } 0.4 \mathrm{mg} \text { OD and } \\
\text { Finasteride } 5.0 \mathrm{mg} \text { OD }\end{array}$ & $\begin{array}{l}\text { Long-term Finasteride therapy results in } \\
\text { worsening of ED, effect that is not noticed in } \\
\text { Tamsulosin therapy. }\end{array}$ \\
\hline Fawzi et al. ${ }^{51}$ & Original & 2016 & Egypt & 150 men & $\begin{array}{l}\text { Tamsulosin } 0.4 \mathrm{mg} \text { OD and } \\
\text { Sildenafil } 25.0 \mathrm{mg} \text { OD }\end{array}$ & $\begin{array}{l}\text { Sildenafil combined with Tamsulosin improved } \\
\text { LUTS, erectile function, and quality of life more } \\
\text { than Tamsulosin monotherapy. }\end{array}$ \\
\hline Herberts et al. ${ }^{10}$ & Review & 2016 & USA & - & - & $\begin{array}{l}\text { Watchful waiting is an appropriate for those with } \\
\text { minimal symptoms, as ejaculatory disorders were } \\
\text { seen in } 18 \% \text { of patients using } \alpha \text {-blockers. }\end{array}$ \\
\hline Abrams et al. ${ }^{11}$ & Review & 2009 & USA & - & - & $\begin{array}{l}\text { Treatment may include lifestyle interventions and } \\
\text { behavioral modifications as well as medication } \\
\text { and surgery. Only treatments with clinical } \\
\text { effectiveness should be used. }\end{array}$ \\
\hline Dunn et al. ${ }^{22}$ & Review & 2002 & $\begin{array}{l}\text { New } \\
\text { Zealand }\end{array}$ & - & - & $\begin{array}{l}\text { The data showed that tamsulosin offers } \\
\text { advantages over other } \alpha 1 \text {-antagonists in patients } \\
\text { with LUTS. }\end{array}$ \\
\hline Ren et al. ${ }^{32}$ & Review & 2005 & China & 2455 men & - & $\begin{array}{l}\text { Tamsulosin showed improvement in symptoms } \\
\text { related to BPH. The adverse events of Tamsulosin } \\
\text { were not different to the placebo group. }\end{array}$ \\
\hline Aslan et al. ${ }^{34}$ & Review & 2009 & Turkey & 69 men & - & $\begin{array}{l}\text { The LUTS was significantly associated as a risk } \\
\text { factor for erectile dysfunction. }\end{array}$ \\
\hline Rosen et al. ${ }^{44}$ & Review & 2005 & $\begin{array}{l}\text { USA, } \\
\text { France }\end{array}$ & - & - & $\begin{array}{l}\text { The research firmly established that ED is highly } \\
\text { prevalent in men with LUTS associated to BPH. } \\
\text { Combination treatment with Dutasteride and }\end{array}$ \\
\hline$\underset{50}{\text { Dimitropoulos et al. }}$ & Review & 2015 & Greece & - & - & $\begin{array}{l}\text { Tamsulosin is significantly superior to } \\
\text { monotherapies in terms of symptom } \\
\text { improvement. }\end{array}$ \\
\hline
\end{tabular}

Legend: LUTS = Lower Urinary Tract Symptoms; SHR = Spontaneously Hypertensive Rats; 5-ARI = 5-alpha reductase; BPH = Benign Prostatic Hyperplasia; DHT $=$ Dihydrotestosterone; ED $=$ Erectile Disfunction .

\section{Discussion}

The progression of BPH would be related to sex hormones, which act together after binding on their receptors. Thus, the conversion of 5 - $\alpha$-androstenedione in dihydrotestosterone (DHT) by the 17beta-hydroxysteroid dehydrogenase, is directly related to the proliferation of the epithelial elements of the prostate [2]. In addition, androstenedione is converted by aromatase into estrogen (E1) which is later converted to estradiol (E2). This hormone will bind to estrogen-alpha receptors that regulate cell proliferation in the prostatic stroma of patients with BPH [2, 25-27].

The glandular growth, then, is directly related to the intraprostatic concentration of DHT and E2 throughout the life of a man. Although there is a basal rate of apoptosis, the constant activation of those receptors by sexual hormones propitiates cellular proliferation that causes an unbalance in the prostatic tissue homeostasis [28].

Regarding pharmacokinetics, Tamsulosin has a half-life of 9 to 13 hours in healthy people and 14 to 15 hours in the elderly. The drug is administrated by the oral route, which the time needed to reach the maximum concentration is 4 hours fasting and 6 hours after a meal. The bioavailability of tamsulosin is complete (100\%) and the drug has a $99 \%$ binding rate to plasma proteins, being metabolized in the liver by cytochrome P450 (CYP3A4 and CYP2D6). Elimination occurs from urine (76\%) and feces (21\%) [22].

Androgenic receptors are located in large proportions in the prostate, representing about $90 \%$ of all receptors for sex hormones present in the gland [2]; the most prevalent $\alpha$ receptor subtype is the 1A [26]. On average, prostate stromal proliferation accounts for $80 \%$ of the volume of hyperplasia, while epithelial proliferation accounts for $20 \%$ of that volume. Muscle cells, in turn, correspond to $50 \%$ of the stromal volume of the gland $[23,29]$, where tamsulosin has its effect. In this context, the drug allows the relaxation of the smooth muscle promoting relief of the obstruction in the urethra, decompression of adjacent tissues and improvement of urination $[24,30]$.

Once the tamsulosin molecule binds to the $\alpha 1$-adrenergic receptor, there is an interruption of signal transduction via $G$ protein (PTN-G). In this mechanism, the $\alpha 1 \mathrm{~A}$ subunit of 
PTN-G becomes unable to form the guanosine triphosphate (GTP), which is essential for the activation of phospholipase C. Thus, muscle contraction is inhibited by the absence of calcium $\left(\mathrm{Ca}^{2+}\right)$ release by the sarcoplasmic reticulum and calcium entry into the cell through the ion channels [figure 2] [31], causing the relaxation of the prostatic stroma and, as a consequence, less troubled voiding profile.

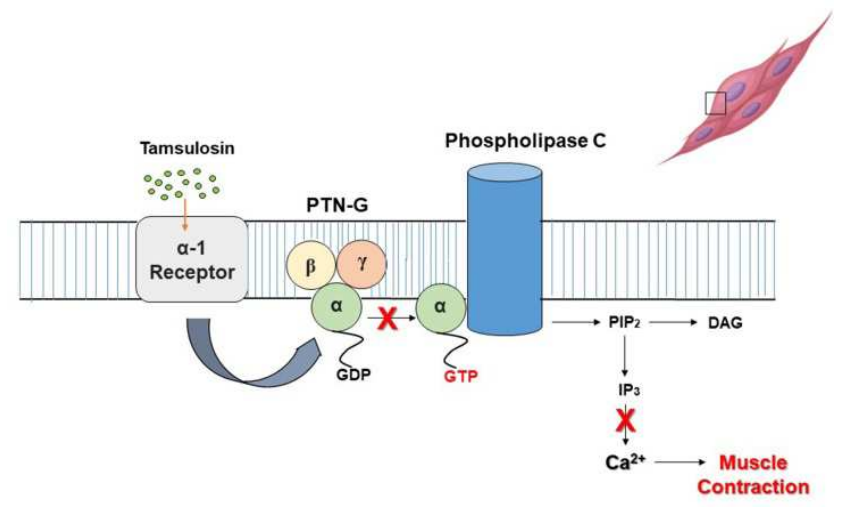

Figure 2. Schematic drawing of the inhibitory action of tamsulosin in calcium release.

Legend: $\alpha=$ Alpha; $\beta=$ Beta; $\gamma=$ Gama; PTN-G = Protein G; GTP = Guanosine triphosphate; GDP $=$ Guanosine Diphosphate; PIP2 = Phosphatidylinositol phosphate; IP3 = Inositol triphosphate; DAG = Diacylglycerol; $\mathrm{Ca}+=$ Calcium.

Wherefore, drug therapy with $\alpha$-blockers aims to decrease urinary resistance so the retrograde pressure on the lower urinary system decreases. This relief prevents the progression of the obstruction caused by BPH to acute urinary retention. Hence, there is a reversal of the reduced flow and the incomplete emptying of the bladder symptoms. $\alpha$-Blockers are also shown to be effective in reducing spasms of the smooth muscle of the prostate and bladder neck, promoting relief and improvement of patients' quality of life [32].

Although tamsulosin is effective for short-term smooth muscle regression, the drug is not able to prevent the conversion of E1 to E2 by the enzyme aromatase, which allows the continued proliferation of the stromal elements. So, the effects of tamsulosin on this route, both during and after discontinuation of the drug, are still uncertain.

Matsushita et al. hypothesized that tamsulosin may still have a beneficial effect in patients with associated erectile dysfunction since $\alpha$-blockers $1 \mathrm{~A}$ also act to relax the cavernous body and allow the necessary blood flow to the erection [33]. Although this study did not identify a significant improvement of erectile function in patients who used tamsulosin, Aslan et al. identified an improvement of erectile dysfunction in patients taking tamsulosin in his study [34].

The evaluation of nocturia in patients with $\mathrm{BPH}$ is contained in the IPSS. Therefore, Yoshida et al. have observed that the administration of tamsulosin guarantees an improvement in this symptom, and hence in the patient's quality of life. It was hypothesized, then, that the lower urinary resistance promoted by the $\alpha$-blocker has an inhibitory effect on the sensitive branch of the urethral nerve, which allows greater complacency of the bladder and greater filling. Thus, increased storage decreases the nocturnal urinary frequency and, in the long term, allows the adjustment of the circadian cycle of regulating hormones, such as vasopressin and atrial natriuretic peptide. The latter promotes fluid reabsorption in the nephron and guarantee less formation of urinary volume [35].

The effect of nocturia on the quality of life of patients with $\mathrm{BPH}$ is reflected in the work of Kim et al. which evaluated the incidence of depression in those patients. Thus, the researcher established that the presence of nocturia is one of the symptoms with the greatest impact on mental health. Such a phenomenon can be triggered by the fragmented sleep and incomplete rest of these patients. Treatment with tamsulosin, however, reverses the symptoms of depression in some patients by improving the nocturia profile and other obstructive symptoms of BPH, making it possible to readjust sleep and improve quality of life [36].

Among the $\alpha$-blockers available for the treatment of BPH (terazosin, doxazosin, alfuzosin, silodosin, and tamsulosin), tamsulosin has reached higher popularity due to its 10 to 12 fold selectivity for subtype 1A receptors over subtype 1B receptors. When compared to the 5-ARI, tamsulosin presents an advantage in relation to the speed of action in the improvement of the urinary flow profile, which can occur in days, while the 5-ARI take months to present its effects [23, 37, 38].

Some studies, however, suggest that the class of alphablockers may be detrimental to various organs that present $\alpha$ receptors $[24,39]$, since the relative specificity of tamsulosin may unbalance the $\alpha$-adrenergic ratio in these tissues. That way, it is corroborated that this may be one of the mechanisms behind some adverse effects, such as the findings relating $\mathrm{BPH}$ to the cognitive deficit, in which higher rates of dementia were found in patients that have taken tamsulosin for a long period of time [40, 41].

Concurrently, there is a correlation between patients with ejaculatory disorders after the use of $\alpha$-blockers, whose explanation is that blockade of $\alpha$-adrenergic receptors in the urinary tract causes relaxation of the smooth muscle of the epididymis, seminal ducts, and vas deferens, which can lose the power of contraction and, therefore, of semen ejection. The ejaculatory disorder resulting from tamsulosin is characterized as retrograde ejaculation [33, 42-51].

In order to recognize tamsulosin as an effective treatment for rapid regression and improvement of the prognosis of patients with $\mathrm{BPH}$ (especially those at risk of developing acute urinary retention), the possible adverse effects suggested by different studies must be evaluated. Therefore, it is recommended to the physician always to consider the desired effects and possible adverse effects, in order to guarantee the best treatment to the patient.

\section{Conclusion}

Studies on the efficacy and adverse effects of tamsulosin 
demonstrated that the drug acts directly on the smooth muscle of the prostatic stroma in order to accomplish a good pharmacological treatment for patients with symptomatic $\mathrm{BPH}$. The epithelial elements, however, do not regress with the administration of tamsulosin and may be involved in the growth of the gland even in patients with regular use of $\alpha$ blockers. Although effective, tamsulosin causes adverse effects of ejaculatory and cognitive origin, which should be carefully assessed. So, it's important to compare the side effects that involve $\alpha$-blockers and 5-ARI, in order to adjust the treatment according to the patient's perspective. Therefore, further studies are needed to determine whether tamsulosin therapy is more effective than 5-ARI therapy.

\section{References}

[1] Egan KB. The Epidemiology of Benign Prostatic Hyperplasia Associated with Lower Urinary Tract Symptoms: Prevalence and Incident Rates. Urol Clin North Am. 2016 Aug; 43 (3): 289-97.

[2] Da Silva MHA, De Souza DB. Current evidence for the involvement of sex steroid receptors and sex hormones in benign prostatic hyperplasia. Res Rep Urol. 2019; 11: 1-8.

[3] Black L, Naslund MJ, Gilbert TD, et al. An examination of treatment patterns and costs of care among patients with benign prostatic hyperplasia. Am J Manag Care. 2006 Mar; 12 (4 Suppl): S99-S110.

[4] Lepor H, Tang R, Meretyk S, et al. Alpha 1 adrenoceptor subtypes in the human prostate. J Urol. 1993 Mar; 149 (3): 640-2.

[5] La Vignera S, Condorelli RA, Russo GI, et al. Endocrine control of benign prostatic hyperplasia. Andrology. 2016 May; 4 (3): 404-11.

[6] Shapiro E, Becich MJ, Hartanto V, et al. The relative proportion of stromal and epithelial hyperplasia is related to the development of symptomatic benign prostate hyperplasia. J Urol. 1992 May; 147 (5): 1293-7.

[7] Toivanen R, Shen MM. Prostate organogenesis: tissue induction, hormonal regulation and cell-type specification. Development. 2017 Apr 15; 144 (8): 1382-98.

[8] Asiedu B, Anang Y, Nyarko A, et al. The role of sex steroid hormones in benign prostatic hyperplasia. Aging Male. 2017 Mar; 20 (1): 17-22.

[9] Alcaraz A, Carballido-Rodriguez J, Unda-Urzaiz M, et al. Quality of life in patients with lower urinary tract symptoms associated with BPH: change over time in real-life practice according to treatment--the QUALIPROST study. Int Urol Nephrol. 2016 May; 48 (5): 645-56.

[10] Herberts M, Butcher M, Kohler T. The Effect of LUTS/BPH and Treatments on Ejaculatory Function. Curr Urol Rep. 2016 Jul; 17 (7): 48.

[11] Abrams P, Chapple C, Khoury S, et al. Evaluation and treatment of lower urinary tract symptoms in older men. $\mathrm{J}$ Urol. 2009 Apr; 181 (4): 1779-87.

[12] Nickel JC, Aaron L, Barkin J, et al. Canadian Urological Association guideline on male lower urinary tract symptoms/benign prostatic hyperplasia (MLUTS/BPH): 2018 update. Can Urol Assoc J. 2018 Oct; 12 (10): 303-12.

[13] Wein AJ, Coyne KS, Tubaro A, et al. The impact of lower urinary tract symptoms on male sexual health: EpiLUTS. BJU Int. 2009 Apr; 103 Suppl 3: 33-41.

[14] McVary, Kevin T. et al. Surgical Management Of Lower Urinary Tract Symptoms Attributed To Benign Prostatic Hyperplasia: Aua Guideline Amendment 2019. J Urol, p. 10.1097/JU, 2019.

[15] Gratzke C, Bachmann A, Descazeaud A, et al. EAU Guidelines on the Assessment of Non-neurogenic Male Lower Urinary Tract Symptoms including Benign Prostatic Obstruction. Eur Urol. 2015 Jun; 67 (6): 1099-109.

[16] Foster HE, Barry MJ, Dahm P, et al. Surgical Management of Lower Urinary Tract Symptoms Attributed to Benign Prostatic Hyperplasia: AUA Guideline. J Urol. 2018 Sep; 200 (3): 612-9.

[17] Gratzke, Christian et al. EAU guidelines on the assessment of non-neurogenic male lower urinary tract symptoms including benign prostatic obstruction. Eur Urol, v. 67, n. 6, p. 1099$1109,2015$.

[18] Karavitakis M, Kyriazis I, Omar MI, et al. Management of Urinary Retention in Patients with Benign Prostatic Obstruction: A Systematic Review and Meta-analysis. Eur Urol. 2019 Feb 14.

[19] Da Silva MHA, Costa WS, FJ BS, et al. The corpus cavernosum after treatment with dutasteride or finasteride: A histomorphometric study in a benign prostatic hyperplasia rodent model. Asian J Androl. 2018 Sep-Oct; 20 (5): 505-10.

[20] Pinsky MR, Gur S, Tracey AJ, et al. The effects of chronic 5alpha reductase inhibitor (dutasteride) treatment on rat erectile function. J Sex Med. 2011 Nov; 8 (11): 3066-74.

[21] Fuentes AV, Pineda MD, Venkata KCN. Comprehension of Top 200 Prescribed Drugs in the US as a Resource for Pharmacy Teaching, Training and Practice. Pharmacy (Basel). 2018 May 14; 6 (2): 43.

[22] Dunn CJ, Matheson A, Faulds DM. Tamsulosin: a review of its pharmacology and therapeutic efficacy in the management of lower urinary tract symptoms. Drugs Aging. 2002; 19 (2): 135-61.

[23] Lepor H. Alpha-blockers for the treatment of benign prostatic hyperplasia. Rev Urol. 2007 Fall; 9 (4): 181-90.

[24] Bird ST, Delaney JA, Brophy JM, et al. Tamsulosin treatment for benign prostatic hyperplasia and risk of severe hypotension in men aged 40-85 years in the United States: risk window analyses using between and within the patient methodology. BMJ. 2013 Nov 5; 347: f6320.

[25] Royuela M, de Miguel MP, Bethencourt FR, et al. Estrogen receptors alpha and beta in the normal, hyperplastic and carcinomatous human prostate. J Endocrinol. 2001 Mar; 168 (3): 447-54.

[26] Prezioso D, Denis LJ, Klocker H, et al. Estrogens and aspects of prostate disease. Int J Urol. 2007 Jan; 14 (1): 1-16.

[27] Fukami M, Homma K, Hasegawa T, et al. Backdoor pathway for dihydrotestosterone biosynthesis: implications for normal and abnormal human sex development. Dev Dyn. 2013 Apr; 242 (4): 320-9. 
[28] Carson C 3rd, Rittmaster R. The role of dihydrotestosterone in benign prostatic hyperplasia. Urology. 2003 Apr; 61 (4 Suppl 1): $2-7$.

[29] Chughtai B, Forde JC, Thomas DD, et al. Benign prostatic hyperplasia. Nat Rev Dis Primers. 2016 May 5; 2: 16031.

[30] Kim JJ, Han DH, Sung HH, et al. Efficacy and tolerability of tamsulosin $0.4 \mathrm{mg}$ in Asian patients with lower urinary tract symptoms secondary to benign prostatic hyperplasia refractory to tamsulosin $0.2 \mathrm{mg}$ : a randomized placebocontrolled trial. Int J Urol. 2014 Jul; 21 (7): 677-82.

[31] Nash DT. Alpha-adrenergic blockers: mechanism of action, blood pressure control, and effects of lipoprotein metabolism. Clin Cardiol. 1990 Nov; 13 (11): 764-72.

[32] Ren RM, Kou M, Lan XX. Efficacy and safety of tamsulosin for the treatment of benign prostatic hyperplasia: a metaanalysis. Chin Med J (Engl). 2010 Jan 20; 123 (2): 234-8.

[33] Matsushita T, Hasegawa T, Nakano M, et al. The Effect of Tamsulosin Treatment on Erectile Functions in Patients with Lower Urinary Tract Symptoms (LUTS) due to Benign Prostate Hyperplasia: Correlation between Improvement of LUTS and Erectile Function. Low Urin Tract Symptoms. 2011 Apr; 3 (1): 15-8.

[34] Aslan G, Cavus E, Karas H, et al. Association between lower urinary tract symptoms and erectile dysfunction. Arch Androl. 2006 May-Jun; 52 (3): 155-62.

[35] Yoshida M, Inadome A, Masunaga K, et al. Effectiveness of tamsulosin hydrochloride and its mechanism in improving nocturia associated with lower urinary tract symptoms/benign prostatic hyperplasia. Neurourol Urodyn. 2010 Sep; 29 (7): 1276-81.

[36] Kim KS, Jang EY, Kim YT, et al. Tamsulosin Treatment Affecting Patient-reported Outcomes in Benign Prostatic Hyperplasia-associated Depressive Symptoms. Urology. 2016 Jan; 87: 172-7.

[37] Wurzel R, Ray P, Major-Walker K, et al. The effect of dutasteride on intraprostatic dihydrotestosterone concentrations in men with benign prostatic hyperplasia. Prostate Cancer Prostatic Dis. 2007; 10 (2): 149-54.

[38] Stanczyk FZ, Azen CG, Pike MC. Effect of finasteride on serum levels of androstenedione, testosterone and their 5alpha-reduced metabolites in men at risk for prostate cancer. J Steroid Biochem Mol Biol. 2013 Nov; 138: 10-6.

[39] Frankel JK, Duan Y, Albertsen PC. Is Tamsulosin Linked to Dementia in the Elderly? Curr Urol Rep. 2018 Jul 3; 19 (9): 69.

[40] Duan Y, Grady JJ, Albertsen PC, et al. Tamsulosin and the risk of dementia in older men with benign prostatic hyperplasia. Pharmacoepidemiol Drug Saf. 2018 Mar; 27 (3): 340-8.
[41] Becher KF, Madersbacher S, Michel MC. Do benign prostatic hyperplasia drugs affect mood or cognition?. Urologe A. 2019 Mar; 58 (3): 248-53.

[42] Choi JH, Hwa JS, Kam SC, et al. Effects of tamsulosin on premature ejaculation in men with benign prostatic hyperplasia. World J Mens Health. 2014 Aug; 32 (2): 99-104.

[43] Kim SW, Lee WC, Kim MT, et al. Effects of low-dose tamsulosin on sexual function in patients with lower urinary tract symptoms suggestive of benign prostatic hyperplasia. Korean J Urol. 2013 Oct; 54 (10): 697-702.

[44] Rosen RC, Giuliano F, Carson CC. Sexual dysfunction and lower urinary tract symptoms (LUTS) associated with benign prostatic hyperplasia (BPH). Eur Urol. 2005 Jun; 47 (6): 82437.

[45] Yu, Hong-Jeng, et al. Non-inferiority of silodosin to tamsulosin in treating patients with lower urinary tract symptoms (LUTS) associated with benign prostatic hyperplasia (BPH). BJU int. 108.11 (2011): 1843-1848.

[46] Seo, Deok Ha, Sung Chul Kam, Jae Seog Hyun. Impact of lower urinary tract symptoms/benign prostatic hyperplasia treatment with tamsulosin and solifenacin combination therapy on erectile function. Korean J Urol. 52.1 (2011): 4954.

[47] Shelbaia, Ahmed, et al. Effect of selective alpha-blocker tamsulosin on erectile function in patients with lower urinary tract symptoms due to benign prostatic hyperplasia. Urol 82.1 (2013): 130-135.

[48] Pande, Satabdi, Avijit Hazra, and Anup Kumar Kundu. Evaluation of silodosin in comparison to tamsulosin in benign prostatic hyperplasia: A randomized controlled trial. Indian J Pharmacol. 46.6 (2014): 601.

[49] Traish, Abdulmaged M., et al. Finasteride, not tamsulosin, increases the severity of erectile dysfunction and decreases testosterone levels in men with benign prostatic hyperplasia. Horm Mol Biol Clin Investig. 23.3 (2015): 85-96.

[50] Dimitropoulos, Konstantinos, and Stavros Gravas. Fixed-dose combination therapy with dutasteride and tamsulosin in the management of benign prostatic hyperplasia. Ther Adv Urol. 8.1 (2016): 19-28.

[51] Fawzi, Amr, et al. Sildenafil citrate in combination with tamsulosin versus tamsulosin monotherapy for management of male lower urinary tract symptoms due to benign prostatic hyperplasia: A randomized, double-blind, placebo-controlled trial. Arab J Urol.15.1 (2017): 53-59. 